\title{
PerCursos
}

\section{Presunção da culpa: racismo institucional no cotidiano da justiça criminal em Niterói (RJ) ${ }^{1}$}

\begin{abstract}
Resumo
O presente trabalho tem como intuito investigar como o racismo institucional opera cotidianamente no sistema de justiça criminal no Rio de Janeiro, a fim de compreender seus efeitos nas rotinas organizacionais de forma a contribuir para o encarceramento em massa da população negra. Para a elaboração da pesquisa foram feitos acompanhamentos semanais durante cerca de três meses em audiências criminais na cidade de Niterói (RJ). Essas observações diretas tornaram possível verificar alguns aspectos racializados nos julgamentos assistidos, sendo tais aspectos tão rotineiros que usualmente não são percebidos enquanto tais. Para o desenvolvimento do argumento aqui proposto, serão descritos alguns casos específicos que sintetizam os principais padrões existentes nas audiências. Quatro desses padrões serão analisados: a dinâmica de familiaridade entre os operadores do sistema de justiça criminal; o uso de termos racializados cifrados, como é o caso da palavra "favela"; a presunção de inocência que vale apenas para a narrativa dos policiais; e, por fim, as representações sobre a cor da pele do acusado. Como resultado, percebe-se que os operadores do sistema de justiça criminal atuam com base em perspectivas raciais, revelando uma suspeição racializada que acarreta na presunção da culpa dos indivíduos negros.
\end{abstract}

Palavras-chave: Racismo - Brasil. Organização judiciária penal - Brasil. Suspeição (Direito). Seletividade penal - Niterói (RJ).

\author{
Ana Clara Davila Borges \\ Bacharel em Segurança Pública \\ pela Universidade Federal
}

Fluminense - UFF. Graduanda em

Direito pela Universidade Estácio

de Sá - UNESA.

Brasil

anadborges71@gmail.com

Juliana Vinuto
Doutora em Sociologia pela
Universidade Federal do Rio de
Janeiro - UFRJ. Professora da
Univ. Federal Fluminense - UFF.
Brasil
j.vinuto@gmail.com

\author{
Para citar este artigo: \\ BORGES, Ana Clara Davila; VINUTO, Juliana. Presunção da culpa: racismo institucional no cotidiano da \\ justiça criminal em Niterói (RJ). Revista PerCursos, Florianópolis, v. 21, n.45, p. 140 - 172, jan./abr. 2020.
}

DOI: 10.5965/1984724621452020140
http://dx.doi.org/10.5965/1984724621452020140

${ }^{1} \mathrm{O}$ debate proposto neste artigo decorre do diálogo entre a monografia de conclusão de curso da primeira autora (BORGES, 2019), e os trabalhos produzidos pela segunda autora (VINUTO, 2019), que também foi orientadora da referida monografia. 


\title{
Presumption of guilt: institutional racism in routine at the criminal at Niterói (RJ)
}

\begin{abstract}
This paper aims to investigate how institutional racism operates on a daily basis in the criminal justice system in Rio de Janeiro, in order to understand its effects on organizational routines in order to contribute to the mass incarceration of the black population. For the elaboration of the research, weekly follow-ups were made for about three months in criminal hearings in the city of Niterói (RJ). These direct observations made it possible to verify some racialized aspects in the assisted trials, such aspects being so routine that they are usually not perceived as such. For the development of the argument proposed here, some specific cases will be described that summarize the main patterns existing in the hearings. Four of these patterns will be analyzed: the dynamics of familiarity among the operators of the criminal justice system; the use of racialized encrypted terms such as the word "favela"; the presumption of innocence that applies only to the narrative of the policemen; and, finally, the representations about the color of the accused's skin. As a result, it is perceived that the operators of the criminal justice system act on the basis of racial perspectives, revealing a racialized suspicion that leads to the presumption of guilt of black individuals.
\end{abstract}

Keywords: Racism - Brazil. Criminal judicial organization - Brazil. Suspicion - Law. Criminal selectivity - Niterói-RJ. 


\section{Considerações iniciais}

Um dos desafios em se estudar os mecanismos contemporâneos de reprodução do racismo é a naturalização com que é encarado cotidianamente, o que fortalece o silenciamento em torno do tema. Esse silenciamento faz com que ações e discursos que fortalecem desigualdades raciais não sejam vistos dessa maneira, o que pode causar determinadas reações, como afirmar que se trata de um mal entendido ou criticar os indivíduos e grupos que apontam os racismos sofridos por, presumivelmente, se tratar de uma contestação despropositada. Esse tipo de reação nem sempre ocorre quando o racismo é explicitado em palavras claras, como em xingamentos e apelidos pejorativos, mas é recorrente quando o racismo se baseia no tratamento diferenciado oferecido por instituições quando realizam seus serviços.

A negação e o silenciamento em torno do racismo fazem com que este seja pensado como processo marcadamente individual, mas o que muitos trabalhos observam é que há um tipo específico de racismo, chamado de institucional, que faz com que a qualidade do tratamento oferecido pelas organizações varie de acordo com a cor do indivíduo. Isso significa que os servidores de uma escola (CARVALHO, 2004), uma organização policial (MEDEIROS, 2018), um hospital (WERNECK et al., 2016), dentre outras instituições, podem tratar diferencialmente os indivíduos tidos como fora da norma racial, mesmo que isso não seja percebido por eles. Tal processo ocorre a partir de diferentes formas, como negligência, preconceito inconsciente, uso de estereótipos racistas não intencionais, ou mesmo processos ativos de discriminação, que podem ser disfarçados como sendo o procedimento padrão (ALEXANDER, 2017). Como resultado, observam-se maneiras difusas de produzir desigualdades raciais e, assim, prejudicar concretamente a vida de pessoas negras.

Stokely Carmichael" e Charles V. Hamilton, criadores do termo "racismo institucional", afirmam o seguinte:

\footnotetext{
${ }^{2}$ Stokely Standiford Churchill Carmichael foi um ativista dos Panteras Negras nas décadas de 1960 e 1970. De posição pan-africanista, no final da década de 1970 se mudou para a Guiné e trocou seu nome para Kwame Ture. Dado que o livro referido neste artigo é anterior à modificação de seu nome, mantivemos o primeiro nome do autor.
} 
O racismo é ao mesmo tempo franco e secreto. Ele assume duas formas estreitamente relacionadas: indivíduos brancos agindo contra indivíduos negros, e atos da comunidade branca contra a comunidade negra. Chamamos essas manifestações de racismo individual e racismo institucional. O primeiro consiste em atos manifestos de indivíduos, que causam morte, ferimentos ou destruição violenta de propriedades. Este tipo pode ser gravado por câmeras de televisão; isso pode ser observado com frequência em processos de investigação. O segundo tipo é mais latente, muito mais sutil, menos identificável em termos de indivíduos específicos que cometem os atos. Mas não é menos destrutivo para a vida humana. O segundo tipo se origina na operação de forças estabelecidas e respeitadas na sociedade e, portanto, recebe muito menos condenação pública do que o primeiro tipo. (CARMICHAEL; HAMILTON, 1967, não paginado, tradução nossa).

Dessa forma, o racismo institucional tem uma dimensão material (por exemplo, acesso limitado a políticas públicas que reduzem desigualdades ou a própria escassez de recursos) e de interdição aos espaços decisórios (por exemplo, pouco acesso à informação e menor participação nas tomadas de decisão) (WERNECK et al., 2013). Como afirma Silvio Almeida (2018), instituições materializam formas de socialização que têm o racismo como um de seus componentes centrais, o que fomenta padrões sociais influenciados por dimensões racializadas. Isto é, o racismo institucional se refere à maneira difusa e latente como o preconceito racial se apresenta no funcionamento cotidiano de instituições, "provocando uma desigualdade na distribuição de serviços, benefícios e oportunidades aos diferentes segmentos da população do ponto de vista racial" (LOPEZ, 2012, p. 121).

Isso significa que há processos de discriminação que resultam de mecanismos que operam à revelia dos indivíduos, já que mesmo quando rechaçados por alguns profissionais, os efeitos racializados se mantêm em decorrência do funcionamento estrutural das instituições. Para considerarmos um exemplo: mesmo que um grupo de policiais deseje desenvolver uma atuação antirracista em sua jornada de trabalho, ainda assim, os procedimentos de sua organização irão forçá-los a reprimir prioritariamente territórios em que a maior parte das pessoas é negra e pobre - como favelas ou periferias - em detrimento de espaços em que a população é majoritariamente branca (como 
bairros de classe média). Nas palavras do Relatório do Ministério Público de Pernambuco, intitulado "No País do Racismo Institucional”:

O termo Racismo Institucional surgiu na década de 1960 através do Movimento Negro Norte-americano, mas foi definido apenas na década de 1990 na Inglaterra, como resposta ao assassinato do jovem negro Stephen Lawrence por uma gangue branca. O Relatório Macpherson, documento judicial relativo ao caso, ampliou a questão isolada do assassinato argumentando que não apenas os policiais que lidaram com o caso operaram de forma discriminatória, mas a própria instituição policial acionou dispositivos diversos de leniência que findou, no primeiro momento, com a absolvição de todos os criminosos. (MORAES, 2013, p. 11-12).

Os debates apresentados até aqui discutem o caráter difuso e nem sempre percebido do racismo institucional. Um efeito disso é que raramente as instituições assumem os efeitos racializados de suas ações, o que dificulta a sua responsabilização. Além disso, exceto por alguns movimentos sociais organizados, a própria sociedade dificilmente demanda a responsabilização das instituições. Temos, portanto, um potente silenciamento da questão, que torna ainda mais desafiador compreender como a produção estrutural da desigualdade racial opera atualmente. Como o racismo institucional tem como característica central o fato de não ser elaborado em palavras, e muitas vezes sequer ser percebido pelos indivíduos; usualmente, recorre-se ao tratamento estatístico para que seja possível visualizar o tratamento diferenciado no interior de organizações em razão dos aspectos fenotípicos das pessoas atendidas.

Aqui vale notar o pioneirismo dos trabalhos de Carlos Hasenbalg e Nelson do Valle e Silva (2003), que desde os anos 1970 se utilizaram de ferramentas quantitativas para demonstrar diferenças no que se refere à ascensão social entre brancos e não brancos. Suas análises estatísticas não permitiram observar a discriminação diretamente, mas é inferida ao considerar as disparidades dos resultados dos diferentes grupos raciais, a partir de análises de variáveis de controle relevantes, isto é, a igualdade de outras condições (por exemplo, renda familiar e nível educacional). Marcia Lima (2014) ressalta que dados quantitativos sobre desigualdades raciais são extremamente relevantes, mas 
não suficientes, já que não acessam a maneira como os indivíduos compreendem suas experiências e seu mundo. Nesse sentido, afirma: “Os achados quantitativos constituem um ponto de partida fundamental para os estudos qualitativos, pois muitas respostas para as desigualdades aferidas estatisticamente precisam ser observadas sob uma perspectiva complementar." (LIMA, 2014, p. 928).

Porém, como estudar qualitativamente um fenômeno que não é percebido e, portanto, elaborado oralmente pelos indivíduos? Sobre isso, Lima ressalta:

Creio que as pesquisas qualitativas sobre raça enfrentam desafios de outra natureza. Em muitas situações de pesquisa, obter do entrevistado um relato de preconceito ou nomear como racismo determinadas situações e experiências não ocorre de forma tão inequívoca quanto nas análises de dados. Enquanto os dados nos falam de grupos, o cotidiano nos fala de experiências individuais de discriminação, em contextos específicos. (LIMA, 2014, p. 928).

Há, dessa forma, desafios específicos para se compreender qualitativamente a dimensão institucional do racismo, havendo a necessidade de pesquisas planejadas criativamente para acessar como o racismo opera no cotidiano das instituições. Isso se torna necessário, pois, por mais que existam vários dados estatísticos que comprovem a exclusão, a segregação e a vulnerabilidade que afetam a vida das pessoas negras, ainda há carência de trabalhos com perspectivas qualitativas que entendam as especificidades do racismo institucional (VINUTO, 2019)

Essa complexidade permite compreender que enquanto o racismo intersubjetivo se apresenta de maneira concreta e evidente - a partir de ofensas verbais, por exemplo -, as manifestações do racismo institucional são mais sutis, mas nem por isso com efeitos menos perversos. Tal "sutileza" revela-se enquanto um desafio específico dos estudos qualitativos que buscam compreender a dimensão estrutural do racismo, já que ao mesmo tempo em que se observam padrões estatísticos de exclusão da população negra, percebe-se o desconhecimento sobre essas questões pela maioria da população. Dessa forma, se nem sempre ofensas explícitas são consideradas racismo, mas brincadeiras ou mal-entendidos, o racismo institucional 
enfrenta barreiras ainda maiores para ser compreendido enquanto tal. (VINUTO, 2019, p. 232-233).

Este artigo almeja contribuir com a questão, ao descrever uma pesquisa de campo baseada em observações, na qual foi possível debater algumas dimensões racializadas existentes no sistema de justiça criminal, baseadas, sobretudo, numa suspeição constante, difusa e marcadamente racial. Trata-se de uma pesquisa de caráter exploratório, mas ainda assim extremamente relevante para pensarmos nos desafios das pesquisas qualitativas que se debruçam sobre o racismo institucional no sistema de justiça criminal.

Dentro desse contexto, este trabalho tem como finalidade observar se e como o racismo se reproduz especificamente dentro do sistema de justiça criminal brasileiro. Para tanto, acompanhamos semanalmente audiências entre setembro e novembro de 2019, totalizando mais de 100 sessões observadas, em sua maioria de instrução e julgamento³. As observações foram realizadas no Fórum Desembargador Enéas Marzano, localizado na cidade de Niterói (RJ), a fim de compreender possíveis singularidades no julgamento de pessoas devido à cor de sua pele.

Para expor o argumento aqui proposto, iremos descrever cinco casos observados nas audiências em que os acusados eram negros, para assim ilustrar e sintetizar os principais aspectos do racismo institucional observados durante a pesquisa realizada. Nesses casos, todos os profissionais do sistema de justiça criminal observados eram brancos, o que já foi percebido em outras pesquisas (ALVES, 2015). Em seguida, analisaremos quatro pontos específicos que atravessam a grande maioria dos casos observados, inclusive os aqui descritos, que parecem centrais para sugerir uma suspeição de caráter racializado que se opõe ao princípio da presunção da inocência ( $5^{\circ}$, inciso LVII, da Constituição Federal), o que se revela como dimensão central da seletividade penal.

\footnotetext{
3 “Audiência de Instrução e Julgamento é um ato processual solene e serve, principalmente, para colheita da prova oral (depoimento de partes e/ou testemunhas)." Disponível em: <https://www.aurum.com.br/blog/audiencia-de-instrucao-e-julgamento/>. Acesso em: 03 nov. 2019.
} 


\section{Audiências: alguns casos que ilustram padrões racializados na atuação do sistema de justiça criminal carioca}

\section{Caso número 1}

Início da audiência: 15h47min

Término da audiência: 16 ho5min

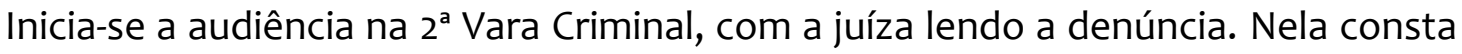
que, no dia citado, dentro da comunidade da Nova Brasília, foi encontrada, em posse dos acusados, uma mochila contendo drogas diversas divididas em pequenas quantidades. $O$ primeiro a depor é um policial que participou da operação. Ele se senta no local indicado e a juíza informa que ele irá prestar depoimento na condição de testemunha de acusação e, dessa forma, deve dizer a verdade, com risco de ser acusado de falso testemunho. A juíza faz perguntas básicas ao policial, como nome, idade e batalhão em que trabalha, e em seguida pergunta se tem conhecimento de algo que o impeça de depor. $\mathrm{O}$ policial responde que não.

A palavra é passada para a promotora, que pede para que ele descreva os fatos contidos na denúncia. O policial começa contando que sua equipe foi chamada com a missão de coibir o tráfico naquela comunidade. Assim que entrou através de um beco, a equipe foi recebida com tiros. Na troca de tiros, alguns indivíduos correram e conseguiram se esconder pelas vielas. O policial conta que, durante a busca, ele e mais um parceiro chegaram a uma casa na qual narra ter visto os acusados entrarem. $O$ policial afirma que ele e seu parceiro encontraram na varanda da casa a mochila citada na denúncia. Chegaram até a porta, entraram e encontraram os dois acusados, que logo se renderam.

A promotora faz poucas perguntas sobre o que foi apresentado pelo policial e logo a juíza passa a palavra para a advogada do réu, chamado Matheus4:

- Advogada: Como era essa casa?

- Policial: Era uma casa dessas de comunidade, com um muro colado no outro.

\footnotetext{
4 Todos os nomes utilizados nesse artigo são fictícios.
} 
- Advogada: A porta estava aberta quando vocês entraram?

- Policial: Sim, por isso eu e meu parceiro entramos.

A advogada diz estar satisfeita e a juíza passa a palavra para o defensor público que está representando o réu Lucas. O defensor pergunta como ocorreu o confronto narrado. O policial responde que foi muito rápido e logo as pessoas correram. O defensor se diz sem mais perguntas.

O policial assina os termos do seu depoimento e sai da sala. Logo em seguida entram os réus, que estão presos há cerca de dois meses, desde o dia do ocorrido. Inicialmente, Lucas sai da sala e Matheus é o primeiro a ser interrogado. A juíza faz perguntas básicas a Matheus, como idade, nome dos pais, estado civil, profissão, se já foi preso ou processado antes, lugar onde mora, com quem mora e se ele estudou. Matheus responde seus dados pessoais, diz que estudou até a oitava série (nono ano atual) e que nunca foi preso ou processado. A juíza pergunta:

- O senhor gostaria de falar sobre o fato ocorrido ou quer ficar calado, sem que cause nenhum prejuízo pro senhor?

- Matheus: Quero falar, sim.

- Juíza: É verdade o fato contido na denúncia?

- Matheus: Não, senhora.

- Juíza: O senhor é traficante?

- Matheus: Não, senhora.

- Juíza: Por que será que policiais inventariam isso?

- Matheus: Eu não sei não, senhora, posso contar o que aconteceu?

Matheus narra que estava em casa, onde mora com a mãe, e que esta não estava presente no momento, quando os policiais invadiram sua casa arrombando a porta. Eles seguravam uma mochila dizendo que a encontraram na varanda da casa e que, portanto, esta pertencia ao acusado. Matheus negou os fatos, ressaltando que qualquer pessoa 
poderia ter acesso à varanda e que a mochila poderia ter sido jogada lá por qualquer um, mas, mesmo assim, foi levado para a viatura, na qual Lucas já estava.

Ao longo de todo depoimento, a juíza fez expressões que demostravam que ela não dava nenhuma credibilidade ao que Matheus falava (olhos virados para cima, sobrancelha arqueada, aparentando impaciência), parecendo que já tinha decidido aquilo que tomaria como verdade. A promotora se diz sem perguntas. A advogada de Matheus pergunta se ele conhecia o outro acusado e ele responde que não. O defensor público também se diz sem perguntas.

Matheus assina o seu depoimento e sai da sala, dando vez ao réu Lucas. Lucas passa pelo mesmo procedimento que Matheus, respondendo as perguntas básicas da juíza, incluindo perguntas sobre escolaridade. Ele responde a todas e diz que não possui o ensino médio completo. Da mesma forma com o outro réu, a juíza pergunta se ele tem interesse em falar sobre o fato. Lucas responde que sim. A juíza pergunta se são verdadeiros os fatos e pede a ele que conte o que aconteceu.

Lucas conta que no dia citado já tinha sido abordado por um dos policiais pela manhã, na barbearia em que trabalha, e ao ser questionado sobre já ter passagem pela polícia, respondeu que sim, pelo artigo 157. No final da tarde, quando houve a troca de tiros, Lucas correu e foi abordado por outro policial. Lucas é soropositivo e portava uma sacola que continha muitos remédios, e nesse momento foi questionado sobre ter passagem, respondendo que não. O policial disse que o levaria apenas para averiguação, mas, quando chegou a viatura, o policial que havia ido à barbearia afirmou que ele tinha passagem, tomou sua sacola de remédios e o deixou sentado na viatura. Algum tempo depois, Matheus foi colocado na mesma viatura que ele. Lucas afirma ter visto a mochila apenas quando chegou à delegacia, quando foi dito pelos policiais que o objeto estava em posse dos dois.

A promotora mais uma vez não formula nenhuma pergunta ao réu. O defensor pergunta por que Lucas mentiu quando foi questionado pelo policial sobre ter passagem logo após os tiros no beco. Lucas responde que preferiu mentir para não levar 
"esculacho5". A advogada de Matheus se diz sem perguntas. A juíza encerra essa audiência e agenda a próxima para ouvir o outro policial.

\section{Caso número 2}

Início da audiência: 15 h38min

Término da audiência: 15h54min

A audiência é iniciada com a vítima - um senhor de meia idade, chamado João entrando e sendo informada pela juíza que seria levada para a sala de reconhecimento. A juíza fala para a vítima que ela pode ficar tranquila, pois a sala possui um espelho especial, que não permite que as pessoas que estão atrás dele sejam vistas. A vítima volta da sala de reconhecimento acompanhada da juíza, que já informa à escrivã que ela não reconheceu ninguém.

João senta-se em frente ao microfone para responder algumas perguntas e registrar o não reconhecimento. A juíza faz perguntas pessoais a João, como nome, idade, profissão e endereço e, em seguida, questiona por que ele não foi capaz de reconhecer ao menos alguma pessoa que o havia roubado. João informa que já se passaram quatro anos do ocorrido e que ele já não se recorda muito bem. A juíza pergunta se havia alguma semelhança entre eles, e sugere: “e quanto à cor da pele?”. A vítima diz que se recorda de todos serem “morenos”. A juíza indaga: “Negros?” A vítima responde que sim. A juíza passa a palavra para a promotora.

A promotora pede a João que descreva o ocorrido, o qual narra que estava almoçando com um amigo, em um restaurante na Região Oceânica, quando um rapaz com uma roupa que descreve ser como um "operário" - entrou e anunciou o assalto. Enquanto este recolhia os pertences dos clientes, outro rapaz "limpava" o caixa e havia também uma criança junto, ameaçando a todos.

A promotora observa nos autos que depois do ocorrido, o senhor havia reconhecido um dos assaltantes em sede policial, e pergunta por que agora ele havia dito

\footnotetext{
${ }^{5}$ Lenin Pires define esculacho como os conteúdos de insulto às substâncias morais das pessoas, indo além do afrontamento ou agressividade: "O termo é empregado para designar situações onde o insulto de alguém dirigido a outro extrapola um limite imaginário, concebido socialmente e praticado em termos rituais" (PIRES, 2010, p. 23).
} 
que não conseguia mais reconhecê-lo. O senhor repete que já se passaram anos do ocorrido e ele não poderia afirmar com certeza. Ele também conta que, na delegacia, o reconhecimento foi feito através de um álbum de fotografias e que todas as fotos eram bastante parecidas, e que por isso não afirmou que era de fato um dos assaltantes, apenas sinalizou que era parecido. A promotora pergunta se ele assinou o termo que comprovava que ele o havia reconhecido. O senhor diz que assinou algo na delegacia, mas confessa não ter lido por completo o que havia assinado devido a todo o nervosismo.

A promotora diz estar satisfeita. A defesa, representada pelo defensor público, diz estar sem perguntas. A juíza marca uma próxima audiência para ouvir outra vítima.

\section{Caso número 3}

Início da audiência: 17 ho5min

Término da audiência: 17h45min

A audiência é iniciada com a promotora lendo a denúncia para os presentes. Nela consta, que no dia citado, na comunidade do Zulu, os denunciados portavam certa quantidade de drogas (maconha e cocaína), dividida em pequenas embalagens e com inscrições referentes à facção. Os policiais foram à comunidade para averiguar denúncias anônimas que receberam sobre o tráfico e foram recebidos com tiros. Avistaram os acusados em um beco e assim que os abordaram eles assumiram que faziam parte do tráfico local. Os acusados portavam além das drogas, uma arma de fogo.

A primeira testemunha é um dos policiais que estavam presentes na operação. $O$ policial se senta no local indicado e a juíza faz perguntas pessoais a ele, como nome, endereço e batalhão em que trabalha. Como em todo caso de depoimento de testemunha, a juíza adverte o policial que deve dizer a verdade, pois está sujeito a pena de falso testemunho. A juíza passa a palavra para a promotora. A promotora pede ao policial que descreva o que aconteceu no dia do ocorrido. O policial diz que aconteceu “conforme consta na denúncia" e, em seguida, conta com suas palavras o que fora descrito acima. A promotora pergunta se o policial já conhecia ou tinha ouvido falar dos acusados anteriormente e ele responde que não. A promotora pergunta como ocorreu a abordagem e o policial responde que, no primeiro momento, não havia visto os acusados, 
porém, com a troca de tiros, eles correram, entrando em um dos becos da comunidade e ele foi atrás deles. A promotora encerra suas perguntas.

A juíza passa a palavra para a defesa dos acusados, representada pela defensoria pública. O defensor pergunta ao policial quantos homens atuaram na operação e ele responde que eram cinco, ao todo. O defensor pergunta a que distância o policial avistou os acusados e ele responde que não sabe precisar. O defensor pergunta por que o policial foi atrás dos dois especificamente, já que havia outras pessoas quando houve a troca de tiros, e o policial responde que foi porque eles estavam fugindo. O policial fala que os abordou no beco e subiu com eles até a "boca" ${ }^{2}$ onde se encontravam os outros policiais que estavam na operação. O defensor fala que é uma presunção do policial falar que eles estavam fugindo, já que eles poderiam estar simplesmente correndo devido à troca de tiros que aconteceu. O policial responde que sua experiência profissional indicava que eles estavam fugindo, e só quem é policial conhece esse tipo de situação. O defensor fala mais uma vez que isso não passaria de um "achismo dele". A juíza intervém perguntando se o defensor teria mais alguma pergunta. O defensor diz estar satisfeito.

O policial assina o termo de depoimento e sai da sala. Um dos réus, Pedro, entra na sala e é direcionado até a cadeira em frente ao microfone. A juíza faz perguntas básicas ao réu, como já mencionado nos outros casos. Dentre as respostas do réu, ressaltamos que ele afirmou ter estudado pouco e que já tinha sido preso anteriormente. A juíza pergunta se ele quer falar ou ficar calado sobre os fatos mencionados. O réu diz que quer falar. A juíza então pede que ele conte o que aconteceu no dia do ocorrido. $\mathrm{O}$ réu diz que não estava com droga nenhuma e que estava parado depois do beco, com o amigo, pois mora ali perto, quando os policiais o abordaram e perguntaram se já tinha "passagem", e ao responder que sim, os policiais falaram que o levariam para a delegacia apenas para averiguação. A juíza passa a palavra para a promotora.

A promotora pergunta se Pedro possui algum apelido e ele responde que não. A promotora pergunta por que ele estava parado se estavam ocorrendo tiros. O réu responde que é "nascido e criado" ali e por isso está acostumado com esse tipo de

\footnotetext{
${ }^{6}$ Gíria referente a ponto de venda de drogas.
} 
acontecimento e achou melhor ficar parado justamente para não o confundirem com "bandido". A promotora pergunta sobre a arma e as drogas e o réu responde que só foi vê-las na delegacia. O defensor se diz sem perguntas.

O réu assina o termo e é retirado da sala. Logo após, o segundo réu, José, entra e se senta em frente ao microfone, para que seja feito o mesmo procedimento do primeiro. O réu responde às perguntas básicas e, ao ser questionado, afirma que não estudou, e posteriormente responde que não "tinha passagem” pela polícia. A juíza também o informa que ele não precisa falar sobre o caso se não quiser, pois não acarretará nenhum prejuízo a ele. O réu diz que quer falar e a juíza pede que ele descreva o ocorrido. O réu conta a mesma história de Pedro: estava conversando com seu amigo no lugar onde sempre morou quando ouviram os tiros, ficaram atentos e logo após foram abordados pelos policiais. Disse que os policiais afirmaram que mesmo não tendo passagem, ele também seria levado para averiguação. Também conta que até chegarem à delegacia não tinha visto nenhuma arma e drogas. A promotora se diz sem perguntas. O defensor também se diz sem perguntas. A juíza finaliza a audiência dizendo que o processo irá para alegações finais.

\section{Caso número 4}

Início da audiência: 14h23min

Término da audiência: 14h35min

A audiência é iniciada com a vítima, chamada aqui de Maria, sendo informada sobre o procedimento de reconhecimento de prováveis culpados pelo crime. Para tranquilizá-la, o juiz explica como funciona o processo. Maria vai para a sala de reconhecimento, acompanhada do juiz, e volta após alguns minutos. O juiz informa ao escrivão que foi negativo. O juiz pede a Maria que se sente em frente ao microfone para responder algumas perguntas. O juiz pergunta por que Maria não reconheceu o acusado, e ela responde que estava muito nervosa na hora do roubo e por isso ficou de cabeça baixa grande parte do tempo. O juiz passa a palavra à promotora.

A promotora pede a Maria para descrever como foi o assalto que sofreu. A vítima conta que estava voltando de uma lanchonete próxima a sua casa com o seu namorado 
da época, quando foram abordados por dois homens em uma moto, que por meio de grave ameaça e emprego de arma de fogo exigiram que eles passassem tudo o que tinham. Os dois deram os celulares e os homens foram embora. A promotora pergunta se eles estavam de capacete ou algo que escondesse o rosto e Maria responde que não. A promotora fala que nos autos consta que a vítima reconheceu um dos acusados quando foi à delegacia, questionando as razões pelas quais ela não o reconhecia mais. Maria diz que, na delegacia, o processo de reconhecimento foi feito através de um álbum de fotografias não muito nítidas, e que hoje vendo pessoalmente as pessoas não consegue afirmar com certeza que foi alguma delas. A promotora pergunta:

- E quanto às características físicas... Cor da pele?

Maria fala que eram negros. A promotora se diz satisfeita.

O juiz passa a palavra para a defesa representada pela defensoria pública. A defensora pergunta se na hora do ocorrido o local possuía bastante iluminação ou estava escuro. Maria responde que tinha pouca iluminação. A defensora diz estar satisfeita. Maria assina os termos do depoimento e do reconhecimento e sai da sala. Logo após, entra Rafael, outra vítima desse assalto e namorado de Maria na época. Rafael também é informado pelo juiz sobre o reconhecimento, e ambos se encaminham para a outra sala. Os dois voltam e o juiz acena para o escrivão que foi negativo. $O$ juiz solicita que Rafael se sente no local indicado para responder as perguntas. $O$ juiz questiona se ele tem certeza sobre o reconhecimento. Rafael responde que sim, que não podia afirmar que era alguma daquelas pessoas de fato. $O$ juiz passa a palavra para a promotora.

A promotora pergunta se ele ficou em dúvida sobre alguém apresentado no reconhecimento, e Rafael responde que teve dúvida do "número dois". A promotora pergunta como foi o reconhecimento na delegacia, já que constava que Rafael havia reconhecido uma pessoa. A vítima responde que foi através de um álbum de fotografias impressas em preto e branco, e indicou apenas uma das pessoas que viu no álbum. A promotora se diz satisfeita e o juiz passa a palavra ao defensor; este se diz sem perguntas. O depoimento é encerrado, Rafael também assina os documentos e sai da sala. 
Fabrício, o acusado, entra na sala e é direcionado até a cadeira em frente ao microfone. O juiz faz as perguntas padrão, e Fabrício diz que estudou apenas até primeira série do ensino fundamental e que não foi preso ou processado anteriormente. O juiz pergunta se o acusado quer falar sobre o fato descrito na denúncia, ou se prefere ficar em silêncio sem que isso the cause prejuízo. O acusado, orientado pelo defensor, responde que prefere ficar em silêncio. O acusado também assina a documentação e sai da sala.

A audiência é encerrada e uma próxima é marcada. Assim que o acusado sai da sala, o juiz, a promotora e o defensor começam a falar abertamente sobre o caso. No meio dessa conversa informal, o defensor fala:

- É fogo esse negócio de reconhecimento por fotografia.

\section{Caso número 5}

Início da audiência: 14h3omin

Término da audiência: 14h57min

A audiência é iniciada com a promotora lendo a denúncia para os presentes. A audiência tem como intuito ouvir as testemunhas de defesa de um dos acusados. Na denúncia consta que os acusados foram presos com drogas e um rádio comunicador em uma comunidade próximo ao bairro Engenho do Mato. Apenas uma testemunha, José, fica na sala após a leitura da denúncia. José tem uma oficina mecânica ao lado do trabalho de Márcio, o acusado. A juíza passa a palavra para a defesa representada pelo defensor público.

O defensor pergunta:

- Há quanto tempo o senhor conhece Márcio?

José: Cerca de seis meses, ele trabalha para o meu vizinho de loja e fazia uns "bicos" para mim, consertando algumas coisas, ajudando em obra, e eu o indicava para conhecidos.

Defensor: Na época em que ele foi preso você mantinha contato com ele? 
José: Sim senhor, ele ia até fazer um serviço pra mim, nunca tinha “furado", e quando ele não apareceu fiquei sabendo que tinha sido preso, fiquei sem entender.

Defensor: Você frequentava a casa dele?

José: Não, mas eu sei onde ele morava, já dei carona até perto pra ele várias vezes.

Defensor: Tem mais alguma coisa que você acha que deva falar?

José: O Márcio era um cara confiável para mim e para todos que fazia trabalhos, tinha a chave da minha casa, ficava com dinheiro de clientes... Nunca tive problema.

O defensor pergunta se José conhece o outro acusado e ele responde que não. $O$ defensor diz estar satisfeito e a juíza passa a palavra à promotora. A promotora pergunta à testemunha se ele percebeu alguma movimentação estranha referente a Márcio. José responde que não e complementa: "se eu tivesse percebido alguma coisa eu não estaria aqui”. A promotora se diz sem mais perguntas. A oitiva de José é encerrada, ele assina o termo de seu depoimento e sai da sala.

A outra testemunha, João, entra na sala e é orientado a sentar em frente ao microfone. Essa testemunha era o patrão de Márcio na oficina de jet ski onde trabalhava. O juiz passa a palavra ao defensor, que pergunta:

- Como era o Márcio no trabalho?

João: Bem tranquilo, nunca tive problema com ele. Tinha total acesso à minha empresa.

O defensor pergunta a João se ele tinha contato com Márcio na época da prisão. João responde que sim, recorda que a prisão de Márcio tinha sido em abril e que nessa época o acusado ainda estava trabalhando com ele. O defensor pergunta quanto tempo o acusado trabalhou para ele e João responde que estava trabalhando já havia seis meses quando foi preso, e fala que sabe que anteriormente João trabalhava em um lugar que trabalhava com eletrônicos. O defensor se diz satisfeito e a juíza passa a palavra à promotora. 
A promotora pergunta a João se ele se recorda de alguma movimentação estranha envolvendo Márcio quando ele estava trabalhando, e João responde que não. A promotora se diz sem mais perguntas. A juíza encerra a oitiva das testemunhas de defesa.

Logo após, entra na sala o primeiro réu, Pedro, que é direcionado à cadeira em frente ao microfone.

A juíza faz as perguntas iniciais a Pedro. Dentre as respostas, Pedro diz ter estudado até o primeiro ano do ensino médio e nunca ter sido preso ou processado anteriormente. A juíza pergunta se o réu gostaria de responder as perguntas sobre o fato ou ficar calado. Pedro diz que gostaria de responder. A juíza pergunta:

- São verdadeiros os fatos narrados na denúncia?

Pedro: Não todos.

Juíza: O senhor é traficante? Está associado ao tráfico?

Pedro: Não senhora, o que é verdadeiro é que eles (os policiais) foram onde eu moro mesmo, acho que estavam procurando outra pessoa, mas não tinha droga nenhuma não.

A juíza, sem olhar para o réu, pede a ele que descreva o ocorrido. Pedro conta que era de manhã cedo quando acordou, escutando os policiais agredindo Márcio. Pedro descreve o lugar onde mora como "vários quartos de solteiro que um cara aluga". Pedro diz que quando saiu do quarto viu os policiais procurando alguém, pois o tempo todo chamavam por alguém com o apelido de "Botafogo". Pedro conta que os policiais o agrediram e disseram coisas do tipo "vou te ferrar". O réu diz que em nenhum momento viu as drogas. A juíza questiona sobre o rádio comunicador e Pedro diz que os policiais pegaram com Márcio. A juíza pergunta sobre sua relação com Márcio. Pedro responde que ele mora no quarto da frente e que o conhece pouco, tendo em vista que mora há pouco tempo naquele local. A juíza, indicando não dar credibilidade à história de Pedro, pergunta:

- Por que os policiais inventariam tudo isso?

- Pedro: Não faço ideia. 
A juíza passa a palavra para a promotora, que se diz sem perguntas. O defensor também, sem perguntas. Pedro assina o termo e é retirado da sala. O réu Márcio entra na sala e é direcionado à cadeira em frente ao microfone. Márcio responde às perguntaspadrão da juíza, e dentre as respostas diz ter estudado até a oitava série (nono ano) e nunca ter sido preso ou processado anteriormente. A juíza também informa que ele pode ficar em silêncio, sem nenhum prejuízo, ou responder as perguntas que serão formuladas. Márcio diz que quer responder. A juíza pergunta se ele é traficante e ele responde que não. A juíza pede que Márcio descreva os fatos ligados à acusação.

Márcio conta que estava em sua casa quando os policiais entraram sem pedir permissão. Vasculharam tudo e encontraram um rádio desmontado dentro de uma caixa, que pertencia a outro vizinho e ele estava consertando. Em seguida, os policiais montaram o rádio e começaram a agredi-lo. Foi nesSe momento que Pedro apareceu, e por isso também teve seu apartamento vasculhado, e os dois foram levados juntos à delegacia. Márcio afirma que apenas na delegacia tomou conhecimento que os policiais afirmaram terem apreendido drogas com eles, além do rádio.

A juíza passa a palavra à promotora, que se diz sem perguntas. O defensor também diz estar satisfeito. Márcio assina seu depoimento e é levado da sala.

Assim que a audiência foi encerrada, a juíza se diz surpresa pelos depoimentos dos réus terem sido os mesmos dados em sede policial. Entretanto, ela mencionou que conhecia bastante o policial que estava à frente na operação, e não conseguia imaginar que ele pudesse inventar qualquer coisa. O defensor discorda da juíza e comenta sobre um caso de roubo grande que ocorreu no hospital onde sua mãe estava internada. 0 defensor diz que nesse roubo houve a participação de um policial para arquitetar, e o principal suspeito era justamente o policial em que a juíza dizia confiar. A juíza fica um pouco surpresa e diz não acreditar que o tal policial possa ter feito aquilo. Os comentários cessam e eles se preparam para iniciar a próxima audiência. 


\section{Análise dos casos apresentados}

Nesta seção discutiremos pontos que sugerem algumas dimensões racializadas existentes no sistema de justiça criminal, a partir dos cinco casos narrados na seção anterior. Como explicado anteriormente, foi possível observar repetições ao longo do montante de audiências que desenhavam um certo padrão. Esse padrão explicita diversos aspectos, alguns sutis e outros nem tanto, pelos quais esse sistema reforça desigualdades raciais. Quatro padrões serão analisados neste trabalho: a dinâmica de familiaridade entre os operadores do sistema de justiça criminal; o uso de termos racializados cifrados, como é o caso da palavra "favela"; a presunção de inocência que vale apenas para a narrativa dos policiais; e, por fim, as representações sobre a cor da pele dos acusados.

\section{A informalidade da família judicial brasileira}

O primeiro ponto que consideramos importante desenvolver é a dinâmica entre os participantes da audiência (juiz/a, promotor/a e defensor/a ou advogado/a), que se revela enquanto uma família (NUÑEZ, 2018). Como foi descrito na seção anterior, esses participantes interagem entre si de maneira pessoal e íntima, muito distante da imparcialidade que se espera em um momento de julgamento que afeta tão drasticamente algumas vidas humanas. Por mais que não seja diretamente ligada ao racismo, esSa forma de interação informal permite que esses agentes coloquem suas opiniões pessoais, podendo fazer com que desconsiderem certos depoimentos de réus em prol de depoimentos de policiais, por exemplo, argumentando que já os conhecem e, por isso, expressam "confiança” pessoal em suas narrativas. Isso faz com que a palavra do policial, mesmo quando não embasado em provas técnicas, seja sempre priorizada, relevando a presunção da culpa de qualquer indivíduo que construa uma narrativa contrária.

A percepção dessa interação é importante porque podemos observar que as concepções meramente pessoais desses agentes influenciam no resultado dos casos. Essa relação informal que os operadores do Direito têm uns com os outros constrói uma dimensão de família judicial. Nessa dimensão, além deles conversarem sobre problemas do dia a dia (observamos entre uma audiência e outras conversas sobre filhos e outros 
assuntos pessoais), mostram também que os problemas referentes aos processos são influenciados pela informalidade. Outros pesquisadores também tiveram essa mesma percepção sobre esses operadores do Direito, relatando como se tratavam como família por se relacionarem bem e "brigarem" apenas quando estivessem fazendo os seus devidos papéis, formando uma “família judicial”. Izabel Nuñez desenvolve esta relação:

O juiz, ao fazer a sua fala inicial, de abertura da sessão, afirmou que "aqui dentro vivemos numa espécie de família, embora desempenhemos funções antagônicas" e "os senhores [jurados] verão que, mesmo discutindo em plenário, depois não temos rancor. Isso nos fortalece enquanto profissionais". (NUÑEZ, 2018, p. 129).

Essa relação informal interfere nos julgamentos realizados. Isso ocorre porque, dada a informalidade e intimidade entre os profissionais que atuam nos julgamentos observados, esses servidores do Estado muitas vezes não se sentem constrangidos em utilizar elementos não técnicos para embasar suas posições, como é o caso da confiança pessoal em determinado policial ou na corporação policial como um todo. Dessa forma, pensar o sistema de justiça criminal como uma família judicial permite compreender "a maneira como esses agentes se relacionam, seja entre eles ou com os casos e com os envolvidos nesses casos e, ainda, como constroem e representam social e moralmente essas relações." (NUÑEZ, 2018, p. 34-35).

Como o uso de provas periciais ou técnicas é quase nulo, e é rara a presença de testemunhas de defesa, os profissionais que atuam nesses julgamentos têm poucos elementos sobre os quais basearem suas conclusões. Nesse sentido, a informalidade e a pessoalidade entre partes que deveriam cumprir funções antagônicas revelam certa influência em seus posicionamentos sobre o caso. Trata-se, dessa forma, de pensar como o valor moral embutido nas representações sobre a família fornece elementos orientadores do fazer judicial cotidiano, atuando de maneira a hierarquizar acusados, testemunhas e vítimas.

Assim, a informalidade da família judicial brasileira não é apenas de caráter corporativo, mas também racial, já que implica em desigualdades de tratamento durante 
o julgamento de pessoas negras. Todos os casos observados foram de acusados negros, o que impede uma análise comparativa sobre o tratamento direcionado a acusados brancos, e tal recorrência revela a brutalidade da seletividade penal. E assim, ao realizar um serviço displicente para um público que é regularmente negro, a informalidade da família judicial brasileira produz assimetrias de acesso à justiça frente ao grupo atendido.

Uma dimensão central para pensar os efeitos de tal informalidade é o tempo dispendido pela família judicial nas audiências. Todas as audiências observadas ocorriam muito rapidamente, sendo conduzidas inclusive de maneira apressada pelos profissionais que aí atuam, como pode ser visto no horário de início e término das audiências descritas anteriormente. A grande maioria dos julgamentos duram em torno de 20 minutos, sendo relevante problematizar se esse tempo é o suficiente para julgar adequadamente um caso.

É importante ressaltar que, segundo Sergio Adorno e Wânia Pasinato:

O tempo é medida da justiça. Se longo, é cada vez menos provável corrigir falhas técnicas na condução administrativa dos procedimentos ou localizar testemunhas, eventuais vítimas, possíveis agressores. Se curto, corre-se o risco de suprimir direitos consagrados na Constituição e nas leis processuais penais, instituindo, em lugar da justiça, a injustiça. Para o cidadão comum, o tempo é lugar da memória coletiva. Se ele consegue estabelecer vínculos entre o crime cometido e a aplicação de sanção penal, experimenta a sensação de que a justiça foi aplicada. (ADORNO; PASINATO, 2007, p. 132).

A morosidade do Poder Judiciário já ganhou status de um problema público, o que pode acarretar casos que se estendem por anos e até prescrevem. Entretanto, isso não ocorre quando há presunção de culpa, momento em que ocorre uma avaliação absurdamente rápida por parte dos operadores do Direito.

Ao longo da pesquisa de campo, foi possível perceber o interesse dos profissionais ali presentes de que aquele procedimento ocorresse de forma rápida, e muitas vezes expressavam, entre um intervalo e outro, a vontade de ir embora e comemoravam quando uma audiência não acontecia por alguma eventualidade. Aqui se verifica que os 
profissionais envolvidos nos referidos julgamentos não estavam interessados prioritariamente em realizar uma avaliação adequada dos casos, mas em terminar seu trabalho no menor tempo possível.

Se concordarmos com Klarissa Platero e Joana Vargas (2017), será possível observar que se destina tão pouco tempo a julgar esses casos porque trata-se de "casos típicos", isto é, são vistos como trabalho de rotina, não acarretando emoções ou empatia. Nesses casos, há uma profecia autocumprida, que pensa jovens negros e pobres, usualmente residentes de favelas, como sujeitos criminais (MISSE, 2011). Em sua pesquisa de campo, as autoras afirmam que a rapidez das perícias referentes ao assassinato de jovens negros indica a desvalorização com que essas mortes são encaradas. Segundo as autoras:

O interessante a analisar nesta descrição é, primeiramente, o tempo de duração da "perícia de local": cerca de 19 minutos entre a chegada das viaturas ao local e a saída das mesmas. Ou seja, a perícia propriamente dita deve ter durado menos de dez minutos. Neste caso, as receitas práticas foram aplicadas de modo muito rápido pelo staff da perícia. A agilidade no que se refere ao modo como os integrantes do staff seguiram as regras de experiência constitui, de um lado, um indicativo de que se tratava de um evento rotineiro, com o qual eles estavam acostumados a lidar e, de outro, do valor moral que o próprio staff atribuíra à vítima, "um usuário de crack". (PLATERO; VARGAS, 2017, p. 629).

Dessa forma, observa-se que a rapidez dos julgamentos pode estar ligada à intimidade entre as partes, que se sentem à vontade para não manejar critérios prioritariamente técnicos para embasar suas perguntas e considerações durante a jornada de trabalho. Além da precariedade das provas técnicas e periciais, a rápida condução das audiências sugere falta de interesse na real apuração dos fatos e acaba por interferir na condenação de muitas pessoas a partir do julgamento que é na maioria das vezes embasado apenas no depoimento do policial (CARVALHO; WEIGERT, 2018). 


\title{
"Favelados" como linguagem racista codificada.
}

Um segundo ponto relevante refere-se à linguagem cifrada (ALEXANDER, 2017) mobilizada pela família judicial para expressar questões de raça sem ter que explicitá-las. No decorrer das audiências observadas, foi comum o policial citar que estava em uma "comunidade"7 para legitimar sua atuação arbitrária e agressiva, como entrar nas residências sem pedir permissão ou agir como se todos os moradores fossem envolvidos com o crime apenas por viverem ali.

O "favelado" passa a ser um elemento-chave na linguagem usada para reproduzir estereótipos raciais, fazendo com que esse grupo de pessoas (residentes de favelas) sempre seja julgado na condição de suspeito quando entra em contato com a polícia, revelando a presunção da culpa com que são abordados constantemente. É importante dizer que a questão da renda no Brasil está diretamente associada à cor da pele, já que, segundo Abdias do Nascimento, a associação entre classe e raça não é mera contingência:

\begin{abstract}
Se os negros vivem nas favelas porque não possuem meios para alugar ou comprar residência nas áreas habitáveis, por sua vez a falta de dinheiro resulta da discriminação no emprego. Se a falta de emprego é por causa de carência de preparo técnico e de instrução adequada, a falta desta aptidão se deve à ausência de recurso financeiro. Nesta teia o afrobrasileiro se vê tolhido de todos os lados, prisioneiro de um círculo vicioso de discriminação - no emprego, na escola - e trancadas as oportunidades que permitiriam a ele melhorar suas condições de vida, sua moradia inclusive. Alegações de que essa estratificação é "não-racial" ou "puramente social e econômica" são slogans que se repetem e racionalizações basicamente racistas: pois a raça determina a posição social e econômica na sociedade brasileira. (NASCIMENTO, 1978, p. 85, grifo do autor).
\end{abstract}

Vemos, assim, que à população negra não foi dado o devido acesso a serviços públicos de qualidade que são direitos de todos, como educação, trabalho digno e

\footnotetext{
7 No Rio de Janeiro é comum mobilizar o termo "comunidade" para se referir prioritariamente a favelas, mas também a outros espaços de pobreza. Para saber mais: BIRMAN, Patrícia. Favela é comunidade? In: SILVA, Luis Antônio Machado (org.). Vida sob cerco: violência e rotina nas favelas do Rio de Janeiro. Rio de Janeiro: Nova Fronteira, 2008. p. 99-114.
} 
moradia. Um estudo feito pelo Ipea, em 2011, informa que 66,2\% dos domicílios nas favelas são chefiados por negros (PINHEIRO et al, 2011). Ou seja, comunidades são espaços racializados e alegar uma repressão maior nesses espaços é efeito de uma compreensão racista desses espaços.

Michelle Alexander (2017) destaca que a discriminação e exclusão dos negros nos EUA não acabaram, mas apenas mudaram de face, já que as formas de exclusão dos negros do convívio social foram se modificando junto com a sociedade. Desprezados e utilizados como força de trabalho nos tempos de escravidão, depois segregados através das leis $\mathrm{Jim}_{\mathrm{Cr}} \mathrm{w}^{8}$ e, agora, sendo criminalizados, rotulados como delinquentes para que através do Sistema de Justiça Criminal continuem a ser penalizados.

Alexander destaca que os EUA ainda não são uma democracia igualitária, e essa questão se reflete principalmente na dimensão da raça, devido a essas novas formas legalizadas de discriminação. Dessa forma, a autora explica que a linguagem usada para expressar o racismo também mudou (ALEXANDER, 2017), pois como não é mais permitido usar apenas o fator da cor da pele para declarar intolerância a essas pessoas, o Estado criou formas de criminalizá-las para manter as mesmas práticas de segregação. A autora desenvolve o argumento de que a Guerra às Drogas foi utilizada como uma justificativa para perseguir e prender negros, os deixando mais uma vez de fora da vida plena em sociedade. Ela mostra que a Guerra às Drogas teve seu início justamente quando o uso de drogas ilegais estava caindo nas estatísticas americanas. Alexander destaca o fato de o encarceramento em massa provocado com essa "guerra" ser direcionado predominantemente para pessoas negras, enquanto é comprovado que pessoas brancas e negras vendem e usam drogas na mesma intensidade.

Assim, com os negros sendo vistos pelos agentes do Estado e pela sociedade como criminosos por pressuposto, constrói-se uma nova forma de legitimar preconceitos e segregações. A partir do momento em que o negro é tido como suspeito, se torna

\footnotetext{
$8 \mathrm{Jim}$ Crow Laws foi como ficou conhecido um conjunto de leis promulgadas em alguns estados dos EUA que oficializaram e regularizaram a segregação racial. Existiam escolas diferentes para brancos e negros, ônibus e até mesmo bebedouros. Essas leis vigoraram de 1876 a 1965.
} 
aceitável discriminá-lo, porque as pessoas passam a acreditar que uma pessoa que comete um crime não merece mais ter seus direitos garantidos.

No Brasil, o estereótipo do negro morador de favela é constantemente associado ao crime pela polícia e pela sociedade. Por intermédio dos casos contados na seção anterior, foi possível perceber que os policiais já consideram os moradores suspeitos a partir do momento em que entram na comunidade, e qualquer trejeito ou forma de agir será interpretado como um indício de ligação ao crime, especialmente o tráfico de drogas. Isso explica a forma de abordagem que o policial implementa em uma comunidade, que jamais será a mesma em algum bairro nobre da cidade (RAMOS et al., 2004). Em uma comunidade, um jovem correndo será considerado pela autoridade policial um indício de que se trata de um traficante, o que não ocorrerá em um bairro rico ou de classe média.

Dessa forma, podemos perceber que os estereótipos raciais influenciam as tomadas de decisão das organizações de segurança pública (ALEXANDER, 2017), produzindo cada vez mais um controle dessa população considerada indesejável, produzindo encarceramento em massa. Esse encarceramento em massa seria, como explica Alexander, um controle legalizado.

Dessa forma, podemos concluir esse ponto trazendo a reflexão de que, se os negros são os mais perseguidos pela polícia devido ao estereótipo racial que orienta a suspeição dos policiais, tal repressão ocorrerá ainda mais nas comunidades, pois são lugares habitados predominantemente por negros, como já explicitado no começo desta seção. Haveria, nesse sentido, uma "demonização dos residentes de favela" (VINUTO, 2019), que padroniza todas as pessoas que vivem lá como criminosas e, assim, o policial acredita ser justificável e natural entrar em uma casa em uma comunidade sem pedir permissão, utilizando o argumento de combate ao crime e da guerra às drogas.

\section{A presunção de inocência que vale apenas para o policial}

Outro ponto central nas audiências é a centralidade dos depoimentos dos policiais. Estes estavam presentes na maioria das audiências como testemunhas de acusação, por terem participado das devidas ocorrências. No desenrolar das audiências foi possível 
observar que tais depoimentos afetavam fortemente os resultados do processo, a partir do momento em que aquilo era tomado como verdade absoluta, fazendo com que os juízes não se mostrassem interessados na versão do réu ou de alguma testemunha de defesa (quando havia, dada sua presença em raríssimos casos).

Quando qualquer pessoa depõe, Ihe é comunicado que deve dizer a verdade ou poderá ser acusada de falso testemunho. Mas em que medida os depoimentos dos policiais são integralmente confiáveis a ponto de não se considerar outros depoimentos? Mesmo quando houve elementos contrários à narrativa do policial, comentários como "conheço esse policial, não consigo imaginar que ele pudesse inventar qualquer coisa" (ver relato 5) revelam como a relação pessoal, típica da dinâmica da família judicial, interfere de maneira profunda no desenrolar do processo. Isso nos leva a perceber que, independentemente de os fatores apontarem outras possibilidades de julgamento, é o depoimento do policial que valerá como principal prova do processo. Tal fator está diretamente associado à pouca ou nenhuma quantidade de provas técnicas, o que faz com que efetivamente o julgamento se oriente apenas por um depoimento tido como verdadeiro por pressuposto.

Essa confiança cega nos relatos dos policiais é elemento central para compreendermos a seletividade penal, cujo início do processo decorre de abordagens policiais que reprimem estatisticamente mais negros do que brancos (SINHORETTO; MORAIS, 2018), revelando como a presunção da culpa atravessa as interações entre negros e instituição policial. Através dos depoimentos dos policiais foi possível perceber que as abordagens não seguem nenhum tipo de protocolo e partem exclusivamente da percepção individual do agente de polícia, que usualmente justifica sua ação com base no argumento do "faro policial" (RAMOS et al., 2004) ou "tirocínio" (SCHLITTLER, 2016). Entretanto, são argumentos como esses que sustentam a ideia de um suspeito em potencial, que será identificado no geral como homem, jovem, pobre e negro.

Além dessa suspeição que recai prioritariamente sobre um determinado público, foi possível observar a existência de um "estigma de bandido": uma vez que a pessoa abordada, principalmente quando já teve passagem pela polícia anteriormente, não conseguirá se libertar do rótulo de "bandido", como se essa pessoa fosse essencialmente 
criminosa e não houvesse alternativa além de ser criminosa. Isso produz um ciclo de suspeição-abordagem-acusação, revelando processos de sujeição criminal (MISSE, 2011) que contribuem de maneira expressiva para a seletividade penal.

Com isso, podemos entender que, devido à falta de provas e à confiança cega e exclusiva nas narrativas construídas por policiais, a audiência se desenrola com o intuito de apenas confirmar a história do policial, sem questionar as possibilidades deste de estar manipulando os fatos. Essa confiança total é racializada, pois desconsidera a seletividade penal, ilustrada por abordagens de cunho discriminatório que focam a sua atenção em uma parcela bem definida da população, em territórios também racializados. Ao réu, desde o início, já é atribuída a culpa.

\section{“Cor da pele" como característica principal da suspeição}

O último ponto a ser analisado a partir das observações de campo é o mais evidente e gritante do racismo institucional no sistema de justiça: a cor da pele em si mesma, sendo aberta e diretamente citada como elemento de suspeição. Isso fica claro nos muitos casos em que os operadores do sistema de justiça mostraram de maneira clara o interesse em saber a cor da pele do indivíduo, como se essa característica pudesse encaminhar a resolução do caso.

Dentre um ramo enorme de características físicas que poderiam ser perguntadas à vítima - como altura, tipo corporal (gordo ou magro), cor do cabelo ou se tinha alguma marca que chamasse atenção (alguma cicatriz ou tatuagem) - a primeira característica questionada - e, muitas vezes, a única - foi a cor da pele do indivíduo. Esse fator se evidencia nos momentos em que a vítima confirmava que o indivíduo era negro, pois parecia que nesse instante tudo havia sido solucionado (ver especialmente relato 4). A partir dessa resposta, que parecia esperada, todas as outras possíveis perguntas não precisavam ser feitas, pois já era possível enquadrar o acusado como culpado. Outra observação que revela o foco na cor da pele do indivíduo era o fato de muitas vezes a vítima mencionar a iluminação precária no lugar do ocorrido, e a esse fato não ser dada a devida importância, mesmo quando poderia mudar completamente o rumo do caso devido à falta de condições adequadas para a vítima afirmar com certeza suas convicções. 
Ana Flauzina (2006) nos lembra que o Estado brasileiro utilizou recorrentemente de meios para que o negro fosse eliminado da sociedade, e por isso sugere a existência de práticas de genocídio contra a população negra, principalmente suas camadas mais jovens. Essas práticas genocidas foram alteradas ao longo dos anos para se adaptar aos novos tempos, e assim percebe-se que "o projeto de extermínio da população negra encontra espaço para sua renovação dentro das promessas vazias da modernidade." (FLAUZINA, 2006, p. 100). A autora analisou as várias formas pelas quais o Estado, através do racismo, reproduziu práticas genocidas nem sempre declaradas, sendo as mais nítidas a morte e o encarceramento. Flauzina constatou que as taxas de homicídio em confronto policial e de encarceramento aumentam constantemente, e em ambos os casos o perfil que mais aparece é o de jovens negros:

\begin{abstract}
Assim, seja pela ação da polícia, dos grupos de extermínio, dos agentes penitenciários e dos próprios presidiários, seja pela estigmatização imposta aos indivíduos após a passagem pelo aparelho penal - as promessas de vingança levadas a efeito entre grupos de jovens traficantes e tantas outras cenas para que já sinalizamos em outra oportunidade -, o fato é que [...] o sistema penal é, certamente, o aparelho que dá sustentação a essa amostra significativa do campo minado construído em torno da juventude negra brasileira. (FLAUZINA, 2006, p. 113).
\end{abstract}

Nesse sentido, o alto poder de decisão da polícia, que é responsável por procedimentos mais violentos em certas áreas, baseados em estereótipos racistas, é confirmado pelas decisões do sistema de justiça, que também é responsável pela forma de atuação policial ao legitimar a forma como reprime diferencialmente pessoas negras.

\title{
Considerações finais
}

O objetivo deste artigo foi o de compreender, a partir de ferramentas metodológicas qualitativas, como o racismo institucional opera cotidianamente no sistema de justiça criminal no Rio de Janeiro. A partir de uma articulação entre trabalho de campo e discussões conceituais, foi possível debater como o racismo institucional se 
revela como parte integrante das organizações, sendo, dessa maneira, visto como fenômeno coletivo constitutivo de procedimentos corriqueiros na jornada de trabalho dos operadores do sistema de justiça criminal. Tal situação contribui para a construção de padrões discriminatórios na distribuição e na eficácia das leis penais, criando, por sua vez, desigualdades raciais.

Nesse sentido, este trabalho apresentou a descrição de algumas audiências, a fim de ressaltar algumas dimensões racializadas que, ao se apresentam de maneira difusa, nem sempre são levadas seriamente em consideração. Como ressalta Michelle Alexander, há formas de atuação racistas que em um primeiro momento não parecem ter relação com discriminação racial, mas que, a partir de um olhar analítico adequado, se revelam como fortemente atreladas à percepção de raça. Este artigo discutiu algumas dessas questões, revelando a centralidade do racismo institucional para a perpetuação de uma atuação racista invisível, mas fortemente presente.

Dessa forma, discutir racismo institucional no sistema de justiça é também discutir privilégio branco. Pessoas brancas não se enquadram nos estereótipos de criminosos, e consequentemente não são o alvo principal do sistema penal, sendo abordadas de maneira diferenciada quantitativa e qualitativamente. Assim, este texto almeja relembrar que o racismo é relacional e, ao priorizar a repressão à população negra, o Estado deixa de responsabilizar pessoas brancas. Para a construção de um sistema de justiça criminal será necessária uma atuação institucional claramente antirracista, em que a igualdade de tratamento tão valorizada pela Declaração Universal dos Direitos Humanos seja plenamente realizada.

\section{Referências}

ADORNO, Sérgio; PASINATO, Wânia. A justiça no tempo, o tempo da justiça. Tempo social, São Paulo, v. 19, n. 2, p. 131-155, 2007.

ALEXANDER, Michelle. A nova segregação: racismo e encarceramento em massa. São Paulo: Boitempo, 2017.

ALMEIDA, Silvio. O que é racismo estrutural? Belo Horizonte: Letramento, 2018. 
ALVES, Enedina. Rés negras, judiciário branco: uma análise da interseccionalidade de gênero, raça e classe na produção da punição em uma prisão paulistana. 2015. Dissertação (Mestrado em Ciências Sociais) - São Paulo, Pontifícia Universidade Católica de São Paulo, São Paulo, 2015.

BORGES, Ana Clara D. Presunção da culpa: um estudo sobre racismo institucional no sistema de justiça criminal no Rio de Janeiro. 2019. Trabalho de Conclusão de Curso (Graduação em Segurança Pública e Social) - Instituto de Estudos Comparados em Administração de Conflitos, Universidade Federal Fluminense, Niterói, 2019.

CARMICHAEL, S.; HAMILTON, C. Black power: the politics of liberation in America. New York: Vintage, 1967.

CARVALHO, Marília P. de. Quem são os meninos que fracassam na escola. Cadernos de Pesquisa, São Paulo, v. 34, n. 121, p. 11-40, 2004.

CARVALHO, Salo; WEIGERT, Mariana de A. B. "Making a Drug Dealer": o impacto dos depoimentos policiais e os efeitos da Súmula $n^{\circ} 70$ do TJRJ na Construção do Caso Rafael Braga. Revista de Estudos Criminais, Porto Alegre, n. 68, p. 45-77, jan./mar. 2018.

FLAUZINA, Ana. Corpo negro caído no chão: o sistema penal e o projeto genocida do estado brasileiro. 2006. Dissertação (Mestrado em Direito) - Faculdade de Direito, Universidade de Brasília, Brasília, 2006

HASENBALG, Carlos; SILVA, Nelson do Valle e. Origens e destinos: desigualdades sociais ao longo da vida. Rio de Janeiro: luperj: UCAM: Topbooks: Faperj, 2003.

LIMA, Márcia. A obra de Carlos Hasenbalg e seu legado à agenda de estudos sobre desigualdades raciais no Brasil. Dados, Rio de Janeiro, v. 57, n. 4, p. 919-933, dez. 2014.

LÓPEZ, Laura Cecília. O conceito de racismo institucional: aplicações no campo da saúde. Interface - Comunic., Saúde, Educ., Botucatu, v. 16, n. 40, p. 121-34, jan./mar. 2012.

MEDEIROS, Flávia. Linhas de investigação: uma etnografia das técnicas e moralidades numa Divisão de Homicídios da Policia Civil do Rio de Janeiro. Rio de Janeiro: Ed. Autografia, 2018.

MISSE, Michel. O papel do Inquérito policial no processo de incriminação no Brasil: algumas reflexões a partir de uma pesquisa. Revista Sociedade e Estado, Brasília, v. 26, n. 1, jan./abr. 2011.

MORAES, Fabiana. No país do racismo institucional: dez anos de ações do GT Racismo no MPPE. Recife: Procuradoria Geral de Justiça, 2013. 
NASCIMENTO, Abdias. O genocídio do negro brasileiro: processo de um racismo mascarado. Rio de Janeiro: Paz e Terra, 1978.

NUÑEZ, Izabel S. “Aqui não é casa de vingança, é casa de justiça!": moralidades, hierarquizações e desigualdades na administração de conflitos no tribunal do júri da comarca do Rio de Janeiro. Rio de Janeiro, 2018. Tese (Doutorado em Antropologia) Instituto de Ciências Humanas e Filosofia, Universidade Federal Fluminense, 2018.

PINHEIRO, Luana et al. Retrato das desigualdades de gênero e raça. Brasília: IPEA: SPM: UNIFEM, 2008.

PIRES, Lenin. Arreglar não é pedir arrego: uma etnografia de processos de administração institucional de conflitos no âmbito da venda ambulante em Buenos Aires e Rio de Janeiro. Rio de Janeiro, 2010. Tese (Doutorado em Antropologia) - Universidade Federal Fluminense, Instituto de Filosofia e Ciências Humanas, 2010.

PLATERO, Klarissa Almeida Silva; VARGAS, Joana Domingues. Homicídio, suicídio, morte acidental...'O que foi que aconteceu?' Dilemas-Revista de Estudos de Conflito e Controle Social, São Paulo, v. 10, n. 3, p. 621-641, 2017.

RAMOS, Silvia et al. Elemento suspeito: abordagem policial e discriminação na cidade do Rio de Janeiro. Rio de Janeiro: Civilização brasileira, 2004.

SCHLITTLER, Maria C. Matar muito, prender mal: a produção da desigualdade racial como efeito do policiamento ostensivo militarizado em SP. 2016. Tese (Doutorado em Sociologia) - Centro de Educação e Ciências Humanas, Universidade Federal de São Carlos, São Carlos, 2016.

SINHORETTO, Jacqueline; MORAIS, Danilo de Souza. Violência e racismo: novas faces de uma afinidade reiterada. Revista de Estudios Sociales, Bogotá, n. 64, p. 15-26, 2018.

VINUTO, Juliana. "O outro lado da moeda": o trabalho de agentes socioeducativos do estado do Rio de Janeiro. 2019. Tese (Doutorado em Sociologia) - Instituto de Filosofia, Letras e Ciências Humanas, Universidade Federal do Rio de Janeiro, Rio de Janeiro, 2019.

WERNECK, Jurema et al. Racismo institucional: uma abordagem conceitual. São Paulo: Geledés: Instituto da Mulher Negra: Trama Design, 2013.

WERNECK, Jurema et al. Racismo institucional e saúde da população negra. Saúde e Sociedade, São Paulo, v. 25, p. 535-549, 2016. 
Recebido em: 27/03/2020

Aprovado em: 12/06/2020

Universidade do Estado de Santa Catarina - UDESC

Centro de Ciências Humanas e da Educação - FAED

Revista PerCursos

Volume 21 - Número 45 - Ano 2020 revistapercursos@gmail.com 